\title{
Concept of Value Engineering and Current Project Management Practice in Ethiopian Building Construction Projects
}

\author{
Tsigereda Garomsa ${ }^{1}$, Elmer De Castro Agon ${ }^{2}$, Sintayehu Assefa ${ }^{2, *}$ \\ ${ }^{1}$ Department of Construction Technology \& Management, Wolaita Sodo University, Wolaita Sodo, Ethiopia \\ ${ }^{2}$ Department of Civil Engineering, Jimma University, Jimma, Ethiopia \\ Email address: \\ tsigaredagaromsa55@gmail.com (T. Garomsa), elmer_c_agon@yahoo.com (E. De C. Agon), sintayehua9@gmail.com (S. Assefa) \\ ${ }^{*}$ Corresponding author
}

\section{To cite this article:}

Tsigereda Garomsa, Elmer De Castro Agon, Sintayehu Assefa. Concept of Value Engineering and Current Project Management Practice in Ethiopian Building Construction Projects. American Journal of Civil Engineering. Vol. 7, No. 1, 2019, pp. 1-8.

doi: 10.11648/j.ajce.20190701.11

Received: December 30, 2018; Accepted: February 12, 2019; Published: February 27, 2019

\begin{abstract}
In construction projects, when one-program costs more than planned, decision makers are forced to delay or cancel other activity. Value Engineering can play a key role in overcoming such problems by ensuring programs stay within project duration, estimated budget and saving costs. This study was conducted to assess the applicability of value engineering concept and the current management practice of Ethiopian building construction projects. In this study, knowhow of Ethiopian building construction project experts on value engineering principles were studied and the current management practice was examined. In order to gather required information, questionnaire, interview with project managers and archival review was conducted. Data was analyzed both qualitatively and quantitatively. The result of this study shows, main challenges in the project area were: delay in progress payment by owner, poor site management, weak follow up by consultant, and delay in material delivery from contractor side. Almost all experts in the project have no knowledge on the principle of value engineering and has no willingness to implement the principle. The evaluation made using value engineering principle shows the current management practice was more conventional and the industry is still facing delay of projects, cost overrun and poor quality while there are opportunities to minimize such problems.
\end{abstract}

Keywords: Building Construction, Ethiopian Construction, Project Management, Value Engineering

\section{Introduction}

Project management as defined by project management institute "is the application of knowledge, skills, tools, and techniques to project activities to meet the project requirement" [1]. The main project requirements are time, quality and cost; while considering scope of project and also stakeholders satisfaction or requirement. In order to satisfy stakeholders and meet the requirement, new techniques and approaches were tried by practitioners. Ethiopian construction industry is lagging behind in meeting the project management principles. Because, the industry is still plagued with cost overrun, late completion and delay behind schedule (time overrun). One of the approaches to minimize problems in project management, practiced in many countries is value engineering, which targets on cost minimization [2] while maintaining quality, time (schedule) and safety [3]. This value engineering is believed to be a powerful problemsolving tool.

According to W. T. Chen et al. [2] "Value engineering (VE) is an organized application that uses a combination of common sense and technical knowledge to locate and eliminate unnecessary project costs." While Ethiopia has long history of project management and building construction such as Obelisk of Axum constructed $4^{\text {th }}$ Century AD, Lalibela Rock Hewin churches constructed in $13^{\text {th }}$ Century, Fasiledes (Fasil Gimb) constructed in the $17^{\text {th }}$ Century and many others; the industry is not growing as expected and is not adopting latest project management approaches and techniques. Since the country is in the 
category of least developed, using latest approaches to construct at minimum possible price, with quality and set time is not questionable. Hence, this research is aimed to assess the implementation of Value engineering principles in Ethiopian construction industry and the current practice of project management specifically in Building construction project.

\section{Literature Review}

\subsection{Value Engineering}

World War II was the most destructive war and there was critical material shortage [3]. A team led by Lawrence D. Miles, a staff engineer for General Electric, found that the use of acceptable substitutes were providing equal or better performance at less cost, it launched an effort in 1947 to improve product efficiency by intentionally and systematically developing less costly alternatives [3], it was known as value analysis [5]. The principle was employed by the American department of defense, and used on their shipbuilding programmers of the 1950's and subsequently on the aerospace programmers, the term is replaced as value analysis [6]. According to R. Rachwan [7], unexpected and surprising outcome resulted. Because of this new approach, some of the substitutes reduced costs improved the product, or both. The concept quickly spread through private industry and numerous countries around the world [2] and it was originally termed value analysis or value control [8].

Value is a subjective term and can be defined using different words, such as "desire" "attitude" "preference need" "criteria" and "belief" [9] and has several definitions for various people including "best buy" for a customer, "the lowest cost" for a manufacturer and "highest functionality" for a designer [10]. U. A. Mahadik [8] defined value engineering as "a systematic application of recognized techniques, which identify the functions of the product or service, establish the worth of those functions, and provide the necessary functions to meet the required performance at the lowest overall cost". Generally, Value Engineering intends to provide a client with a trustworthy opportunity for cost savings, time saving, quality improvement [8] and isolation of design deficiencies [9]. According to S. Swetha et al. [3] Value Engineering is not typical cost reduction in that it does not "cheapen" the product or service, nor does it "cut corners." Value Engineering simply answers the question "what else will accomplish the purpose of the product, service, or process we are studying?"

\subsection{Value Engineering Job Plan}

Value Engineering can be applied in any phase of project life cycle [8]. However, applying it on the beginning of the project help for organized implementation of project activities [8]. Value engineering job plan is the key for success and is done by using job plan that is a systematic and organized approach [9]. Different job plans are available and are selected as per suitability of the project and requirements
[9] which are entitled as five phase job plan [8, 10]; six phase job plan [3, 11]; seven phase job plan [9]; eight phase job plan [3]. The eight-phase job plan consists of the following sequential phases.

a. Orientation Phase: - In this phase, the project will be selected and those who are going to participate are familiarized [10].

b. Information Phase: - Maximum information regarding problems is collected [9]. Areas of high cost or low worth are identified [11].

c. Functional Phase: - Analyzing the project to understand and clarify the required functions [11]. It is the activity that differentiate value engineering from other problem solving practices [7].

d. Creative Phase: - It requires a certain amount of creative thinking by the team [3]. That is generating ideas on all the possible ways to accomplish the required functions [11].

e. Evaluation phase: - Value Analysis team judges the ideas developed during the creative phase and the team ranks the ideas $[3,11]$.

f. Development phase: - the best alternatives are selected and prepared [11]. Hence, the final recommendations are developed from the alternatives selected [3].

g. Presentation Phase: - presentation of the best alternative [3] recommendation prepared in the report form [8].

h. Implementation and follow up: - In this phase, management must assure that the recommendations are changed in to action [3].

\subsection{Benefits of Value Engineering}

Value engineering is considered as a very effective approach, which must be understood at all levels of the project management and must be accepted every part of the world [9]. The benefits of this approach are listed by K. Ali et al. [11] in four main categories.

a. Simplification of methods and procedures, which saves time, cost and resource.

b. Better communication and understanding of project objectives leading to better quality work and responsiveness to clients priorities.

c. The client gets opportunity to formally participate on design process. Hence increases, the focus of client to the project.

d. The parties in the industry will have good communication.

\section{Methodology}

The study was conducted in Ethiopia, Addis Ababa saving houses (40/60) project, under construction by grade 3 and above contractors. These projects are available on most subcities of the city; hence, Bole sub-city was selected due to participant's commitment for engagement on the study. The participants were selected by purposive sampling method from different stakeholders of the projects. This sampling size was selected because of less interest of project practitioners to discuss about value engineering principle, 
which is new approach for them. The sample size was determined using method recommended by A. Hayter [12]

$$
\mathrm{SS}=\frac{Z^{2} * P *(1-P)}{C^{2}}
$$

Where SS $=$ Sample size

$\mathrm{Z}=\mathrm{Z}$ value (e.g. 1.96 for $95 \%$ confidence level)

$\mathrm{P}=$ percentage picking a choice, expressed as a decimal ( 0.50 used for sample size needed).

$\mathrm{C}=$ margin of error $(8 \%)$

$$
\mathrm{SS}=\frac{1.96^{2} * 0.5 * 0.5}{0.08^{2}}=150.06 \approx 150
$$

Correction for Finite Sample: -

$$
\text { SSnew }=\frac{S S}{1+\frac{S S-1}{P O P}}
$$

Where: - Total sampled of construction parties $=210$ match the proposed contracting companies (contractors, consultants and clients)

$$
\text { SSnew }=\frac{150}{1+\frac{150-1}{210}}=87.74 \approx 88
$$

The following calculation were used to know the sampling size of each stratum:

SS new for three parties are as follows by systematic sampling

$$
\text { For Contractor: } n_{1=\frac{96}{210} * 88}=40
$$

Forty contractors were selected by using purposive sampling technique.

$$
\text { For Consultant: } n_{2=\frac{74}{210} * 88=} 31
$$

Thirty-one consultant staffs were selected by purposive sampling technique.

$$
\text { For Client: } n_{3=\frac{40}{210} * 88}=17
$$

Seventeen client staffs were also selected by using purposive sampling technique.

In order to collect data, three methods of data collection were adopted: Interview, questionnaire and desk study. Desk study was conducted first for understanding the project management practice and relation among stakeholders. The survey was structured based on stakeholders' category; that is questionnaire used for consultants and contractors; concerning bodies from client were participated by interview.

\section{Analysis and Discussion}

\subsection{Respondents Profile}

From the sample size calculated above, the participants on this research were 28 contractors, 11 consultants and 15 client side experts. In addition, 15 project managers were participated from different projects for interview. The study was conducted on different building construction type. Since the approach is new for the country, $50 \%$ of selected projects were high-rise buildings. The experience of participants was as shown in figure 1 below.

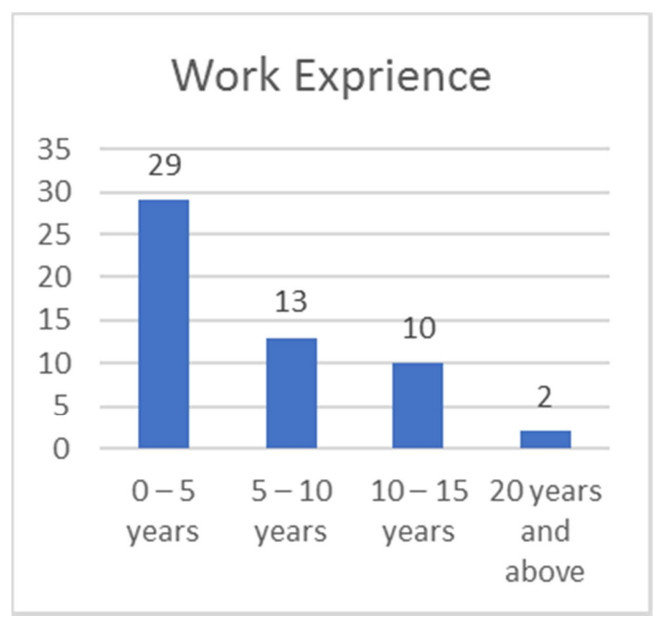

Figure 1. Work Experience of Respondents.

\subsection{Concept of Value Engineering}

One of the challenges the Ethiopian construction industry was facing is traditional method of management. Latest management technologies and approaches utilization was minimal. After finishing desk study, the researcher tried to implement value-engineering principles in companies in order to find out the improvement. However, most of stakeholders were not interested to do so and almost all of the respondents were new for the principle. This is mainly due to the Ethiopian construction industry experts are not flexible to adopt new construction management practices. $63.6 \%$ of respondents believe that their company is using new technologies and approaches for construction. Nevertheless, the desk study shows the management system the industry using was not supported by latest technologies and computerized system. Most of the companies (80.3\%) has scheduled meeting with stakeholders. However, the interview shows that it was not fruitful as expected.

Since the main target of Value Engineering is to minimize cost while improving quality, without time delay. The mechanisms used by companies to bring change and current status of the industry was studied and summarized below.

\subsection{The current Situation of Construction Management in Ethiopia}

\subsubsection{Time Related Factors}

Many factors contribute to the delay of construction project. Delay may occur due to one or combination of many causes. Respondents were asked to score which factors were considered major delay factor in the construction project.

\section{a. Client Related Factors}

Client related factors more fall on financial issue. This comes from bureaucratic process on payment and sometimes shortage of money for government-funded projects. The interview result shows, many change orders were made 
during construction from client side. When change orders were made, price adjustment request by contractors was not accepted by client most of the time and hence delay occurs due to disagreement. The main client related factors are summarized as shown on figure 2 below.

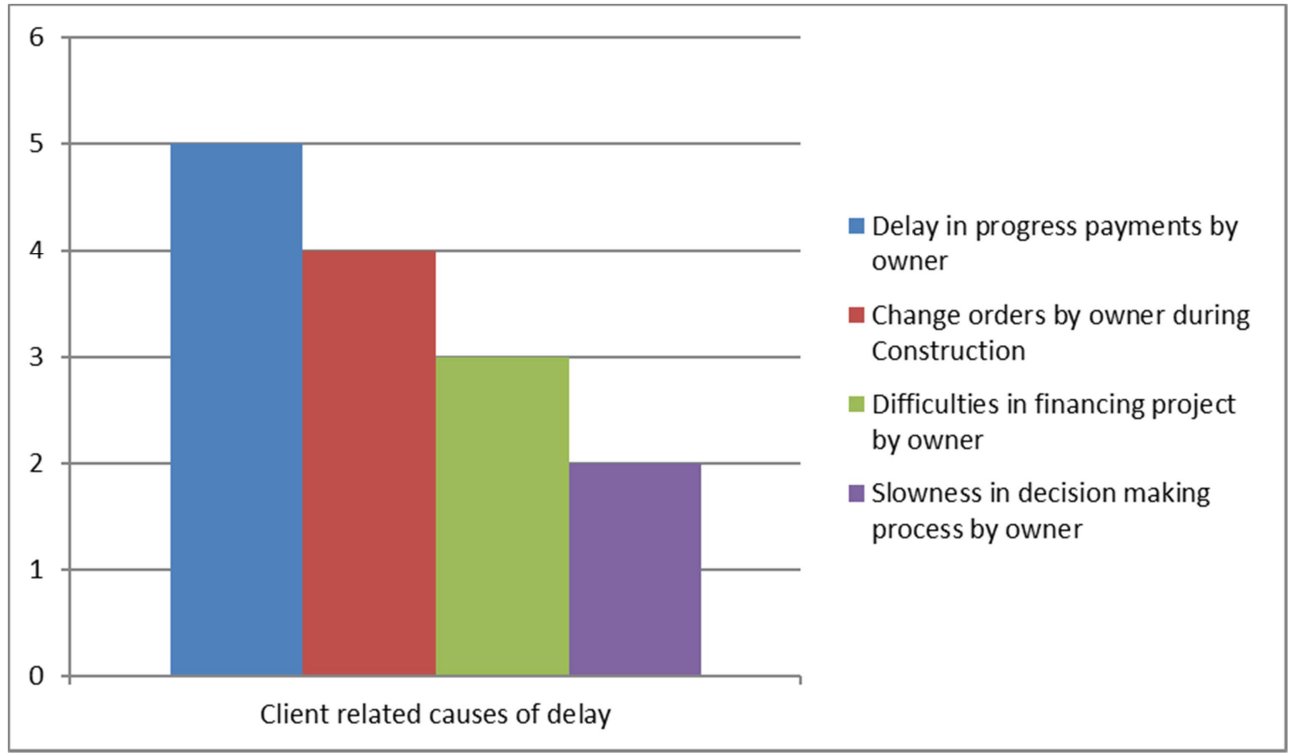

Figure 2. Client Related Delay Factors.

\section{b. Consultant Related Delay Factors}

The consultant is the main player in construction management process. However, contractors and clients blame consultants in poor management and submittal of poor design documents. Interview result from project managers shows, when problems arise at time of supervising; the consultants delay to make decision. Limitations on adaptation of new technologies and lack of experienced expert were the main problems raised at the time of Interview. The main factors collected from questionnaire are summarized as shown on figure 3 below.

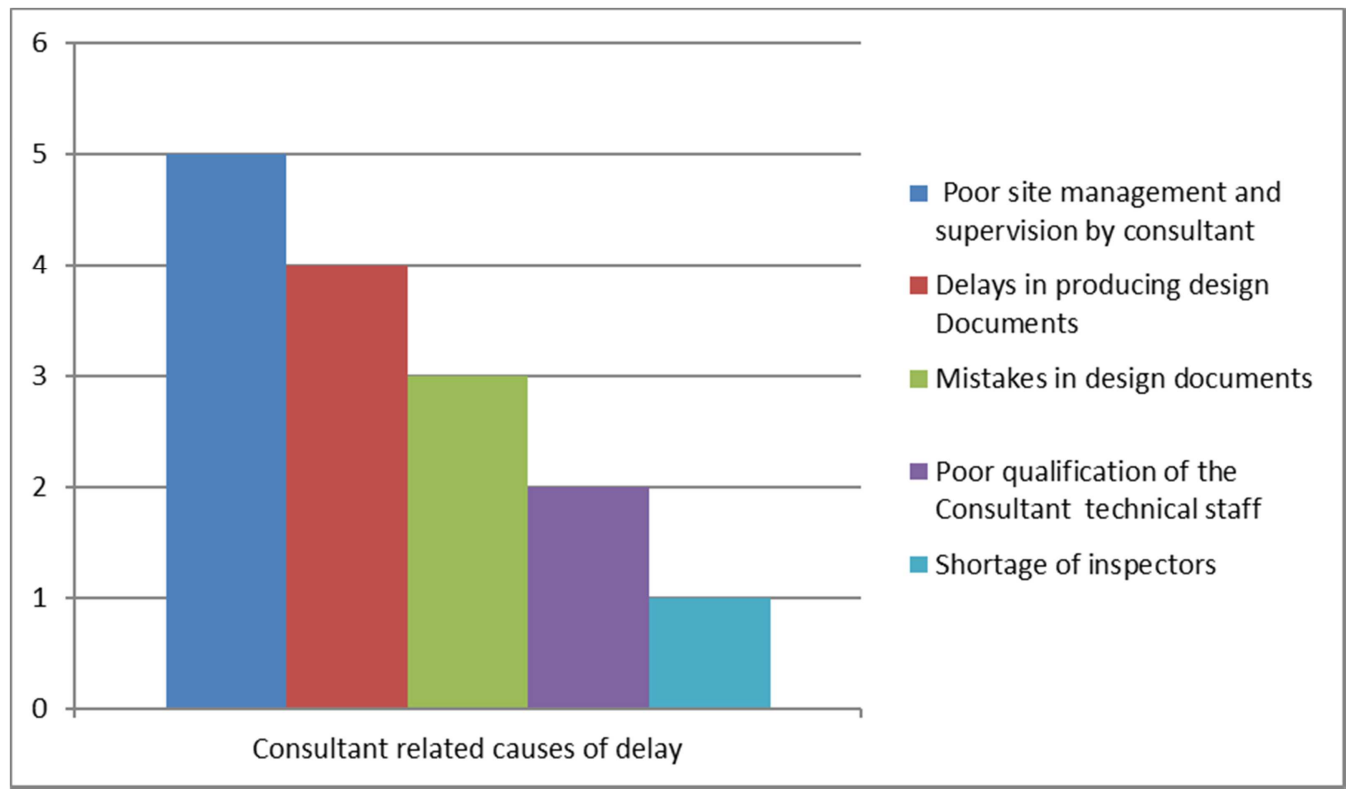

Figure 3. Consultant Related Delay Factors.

\section{c. Contractor Related Delay Factors}

Each project work has predetermined duration with defined beginning and completion time. Therefore, projects are pre-established in time, budget, and quality; to maintain these output proper management is required.

The construction projects may not go smoothly as planned due to different factors, and then delay can occur in projects. Most of stakeholders blame contractors for poor performance of projects in project area and in the country too. The main reasons raised for this poor performance was poor capacity both in finance and experience. Main factors ranked by respondents from questionnaire are summarized in figure 4 below. 


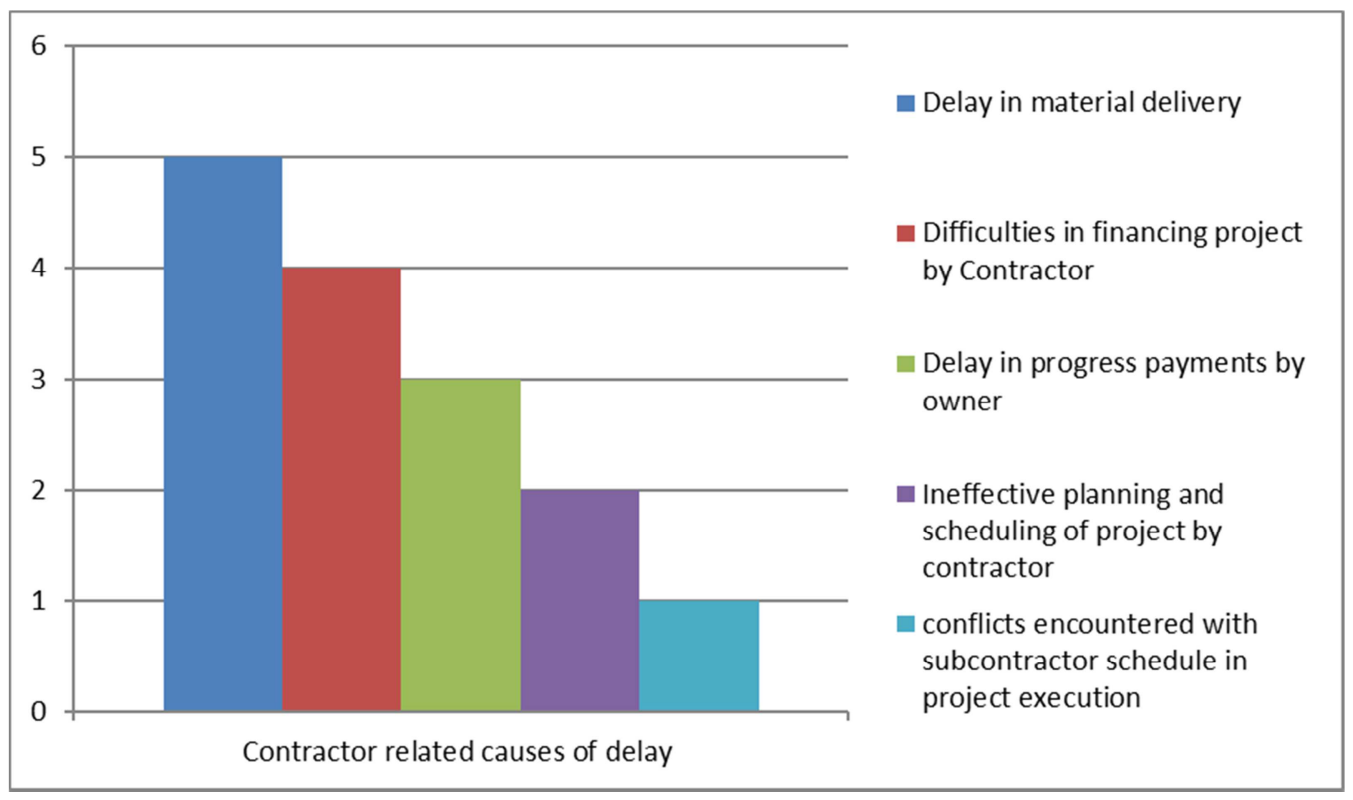

Figure 4. Contractor related delay factors.

\subsubsection{Factors that Increased Poor Quality in Building Construction Project}

The poor quality of buildings constructed in the study area was also considered mainly from three parties point of view. Interview and desk study results indicates; only one or two parties were not responsible for the problems. Contractors related poor quality of construction with, bidding process, supplier problem and shortage of foreign exchange issue. The RII result shows, the belief of consultants, contractors and clients on contractor performance was not similar. Based on Consultants, the top three contractor related factors were incorrect beliefs; improper construction method implemented by contractor and poor quality of materials used by contractor respectively. While the clients believe that, the top three factors were: absence of good coordination, time constraint and dependent on old specification and standards. Contractor perspective was different from other stakeholders. Contractors' ranked, poor quality of materials used by contractor themselves (client was material supplier), absence of coordination among stakeholders and improper construction method implemented by contractor due to weakness of consultant took the first three ranks. Collecting all questionnaires from three parties and analyzing using SPSS 20, the top three contractor related factors were incorrect beliefs; improper construction method implemented by contractor and absence of good coordination respectively.

\subsubsection{Causes of Unnecessary Cost Based on Stakeholders}

One of the main objective of value engineering as well as any good construction management is constructing a structure with good quality and logical time with minimum cost. However, the study area was facing cost overrun throughout the construction activity. These factors may come from different stakeholders. Yet the three main parties are responsible for changes made on construction activity in the study area. Hence, in addition to desk study and interview, the respondents were asked to rank the factors in three categories as summarized below.

a. Contractor related the causes of unnecessary cost

Lack of communication and mutual understanding between consultant and contractors were claims from contractor side. Due to improper design, the consultants bring change order after the construction started and also the consultants did not follow up project progress during construction effectively. Moreover, order for rework after it has been done was the main claim raised from contractors. Finally, the result of questionnaire indicates, rework due to errors during construction, change orders by owner during construction and labor disputes and strikes during construction were the top three factors based on RII value.

\section{b. Consultant related the causes of unnecessary cost}

Consultants on the other hand related the change order mostly come from the client itself. Since most of the time in Ethiopia, Design Bid Build (DBB) method of contract is used, the supervision consultant is different from the designing one. Moreover, the client accepts design document most of the time without checking it well as stated by consultants during interview. After the construction was started, the client brings change orders. The gap created by design consultant was mainly come from lack of information on current material price and latest methods of construction as all parties agreed. The response of participants show; lack of information in respect to materials, methods, and techniques, Change orders by owner during construction and labor disputes and strikes during construction were the top factors.

c. Client related the causes of unnecessary cost

The main gap from client side raised from respondents were; clients were dependent on old and traditional techniques and materials. The client was not flexible for 
change and even resist when consultants and contractors bring new techniques. Yet, the clients bring change order occasionally after the construction was started (as raised by both consultants and contractors). In addition, the clients made mistakes and order for rework during construction activity. The result from collected questionnaire indicate, not using new techniques to reduce cost in the project, rework due to errors during construction and change orders by owner during construction were ranked as top causes for unnecessary cost on construction.

\subsection{Satisfaction of Stakeholders}

One of the main aim of construction project management is satisfying stakeholders. According to S. Assefa [13] disagreements and change in project main targets at the time of construction mostly occur due to the influence and poor engagement of some stakeholders in the project. The researchers tried to investigate the coordination among stakeholders in the study area. The results collected from questionnaire were analyzed using SPSS as shown in the figure 5 below.

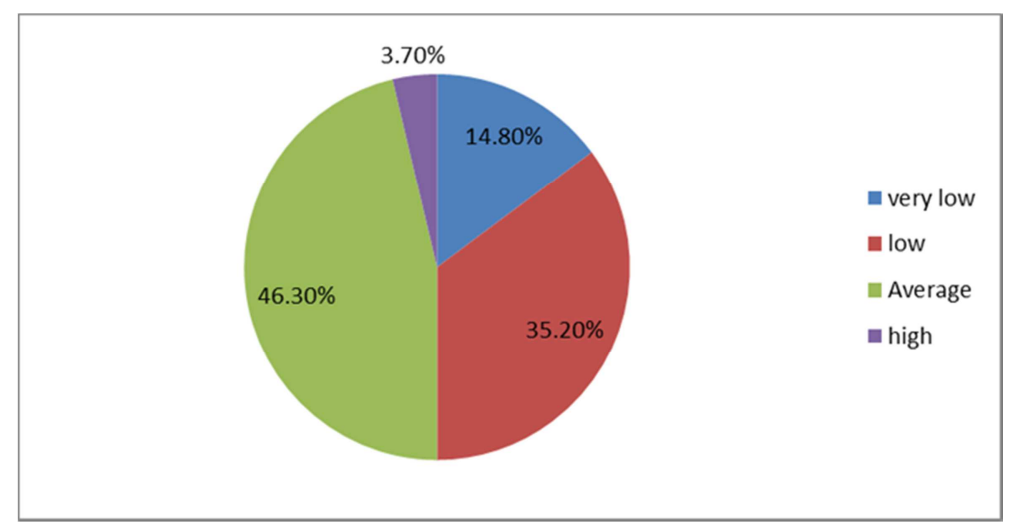

Figure 5. Satisfaction of stakeholders by coordination among them.

The result clearly shows, more than $50 \%$ of project participants of project were not happy with the coordination among them. This is also one factor for poor management of projects and poor progress of structures in meeting the main targets. The poor communication and coordination situation is also common in other African country, Nigeria [14].

The other issue is how much was the satisfaction level of stakeholders with the progress and output of building construction projects. Ninety-two respondents from main parties of construction projects were requested to rate their satisfaction level and 67 returned. Almost all stakeholders' satisfaction was average and below average. In project management, one of the main task is working on stakeholders engagement and satisfaction, [1] the factors for the problems in project were also aggravated due to ignorance of this activity. The result was summarized as shown below on figure 6.

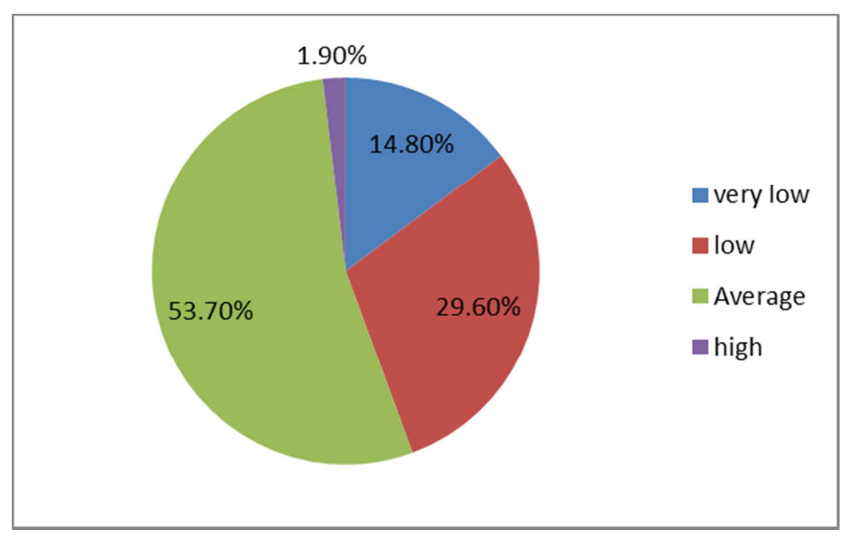

Figure 6. Satisfaction of Stakeholders by Building Construction Progress.

\subsection{Management Practice on Building Construction from Value Engineering Perspective}

Even though, the stakeholders were not interested to practice value engineering and they do not have knowhow about the principles, the researchers tried to evaluate the construction management practice they were using based on value engineering practice checklist. The checklists were prepared based on each phase principles and evaluated by using likert scale.

a. Information Phase: - The information collected includes financial and technical aspects of the projects. All necessary data required were collected through desk study and Interview. After collecting the information, Client, Consultants and contractors were requested to fill the questionnaire if they have culture of collecting information about the project area, stakeholder interest, community interest and the like.

b. Creative Phase: - The researchers tried to look on the available management system and tried to find out the factors that were affecting cost, time, quality and quantity of work. The researchers found that, the culture of using cost and time saving mechanisms was very weak. It has been tried to look on the available options of materials and construction systems. It has been found that, the materials used for construction activities were not satisfactory on quality and also cost saving. The main reason for the situation was materials were supplied by client and the bidding process more dependent on cost and general consideration instead of specific project situations. Hence, questionnaire was prepared and distributed for the parties for rating their own activities using value engineering principle. 
c. Evaluation Phase: - Researchers tried to evaluate the options based on cost \& time saving and quality improving. In order to find out the result, the respondents were asked to evaluate the one they were using with the options prepared by investigation team.

d. Development Phase:-In this phase, investigators tried to evaluate the cost of prepared alternatives with the one supplied by the client. The result shows, it is possible to reduce the material cost while maintaining the quality and reducing time using the value engineering principle. e. Presentation Phase: - The result of the finding was presented for concerning and interested client, consultant and contractor experts. This indicates using value-engineering principle the cost of construction can be reduced and even the quality can be improved.

Conclusion: - the finding and analysis result shows, the principles under analysis phase were done indirectly for the project management. However, the overall usage of principle was very low. The summery of result was analyzed as shown in the table 1 below.

Table 1. Indirectly applied Value Engineering Principles in study area.

\begin{tabular}{|c|c|c|c|c|c|c|c|c|}
\hline \multirow{2}{*}{ Value Engineering Job Plan Phase } & \multicolumn{2}{|c|}{ Contractor } & \multicolumn{2}{|c|}{ Consultant } & \multicolumn{2}{|l|}{ Client } & \multicolumn{2}{|c|}{ Over all } \\
\hline & RII & Rank & RII & Rank & RII & Rank & RII & Rank \\
\hline Analysis Phase & 0.08571 & 1 & 0.07273 & 3 & 0.12 & 1 & 0.2784 & 1 \\
\hline Development Phase & 0.04286 & 4 & 0.16364 & 1 & 0.12 & 1 & 0.1088 & 2 \\
\hline Presentation Phase & 0.04286 & 4 & 0.14546 & 2 & 0.08 & 4 & 0.0894 & 3 \\
\hline Information Phase & 0.07143 & 2 & 0.03636 & 5 & 0.12 & 1 & 0.0759 & 4 \\
\hline Creative Phase & 0.05714 & 3 & 0.07273 & 3 & 0.08 & 4 & 0.0699 & 5 \\
\hline
\end{tabular}

\section{Conclusion and Reccomendation}

\subsection{Conclusion}

The study has clearly shown that, Ethiopian construction industry is still dependent on conventional approach rather than using improved and modern management system. The industry is facing challenges of delay, poor quality, cost overrun, poor engagement and low satisfaction of stakeholders.

The parties in the industry has no know how about the concept of value engineering and has no willingness to practice such type of practices. This is an indication of resistance for new management mechanisms and more trust on conventional approach. Simple study conducted on value engineering principle on some projects shows, it is possible to save cost and time while maintaining quality. However, the parties in the study area were not focusing on the alternatives of reducing cost and construction time.

\subsection{Recommendation}

The main leaders of change are concerning government bodies. Therefore, these bodies should prepare manuals and guidelines on the practice of new management mechanisms. Even though, some of them are trying to give training and bringing new technologies and management practices, attitude change and strategy is necessary to implement those methods and to improve the construction industry in Ethiopia.

\section{References}

[1] PMI Standards Committee, A guide to the Project Management Body of Knowledge [electronic version], Fifth. Atlanta, 2013.
[2] W. T. Chen, P. Y. Chang, and Y. H. Huang, "Assessing the overall performance of value engineering workshops for construction projects,” Int. J. Proj. Manag., vol. 28, no. 5, pp. 514-527, 2010.

[3] S. Swetha;, N. R. Smruthi; , and M. Aleem, "Application of Value Engineering in Building Construction,” Int. J. Adv. Res. Sci. Eng., vol. 5, no. 10, pp. 253-267, 2016.

[4] K. Ilayaraja and M. Zafar Eqyaabal, "Value Engineering in Construction,” Indian J. Sci. Technol., vol. 8, no. 32, pp. 3-10, 2015.

[5] A. Jaapar, "Value management study to the Malaysian construction industry," BEAN 2008 Conf., no. Shen 1995, 2008.

[6] K. H. Allan Ashworth, Added Value in Design and Construction, Second. Newyork: Routledge, 2014.

[7] R. Rachwan, I. Abotaleb, and M. Elgazouli, "The Influence of Value Engineering and Sustainability Considerations on the Project Value," Procedia Environ. Sci., vol. 34, pp. 431-438, 2016.

[8] U. A. Mahadik, "Value engineering for cost reduction and sustainability in construction projects," J. Mech. Civ. Eng., vol. 1, no. NA, pp. 95-97, 2015.

[9] N. T. V Gowrisankar, N. Tom, and V. Gowrisankar, "VALUE ENGINEERING IN RESIDENTIAL HOUSE CONSTRUCTION,” Int. J. Civ. Eng. Technol., vol. 6, no. 6, pp. 46-52, 2015.

[10] A. Sharma and R. M. Belokar, "Achieving Success through Value Engineering: A Case Study," in Preceedings of the World Congress on Engineering and Computer Science, 2012, vol. II, pp. 24-27.

[11] K. Ali, A. Ahmed, and R. K. Pandey, "Concept of Value Engineering in Construction Industry," Int. J. Sci. Res., vol. 5, no. 4, pp. 1231-1237, 2016.

[12] A. Hayter, Probability and Statistics for Engineers and Scientists, Fourth. Denver, 2012. 
Practice in Ethiopian Building Construction Projects

[13] S. Assefa, Z. T. Worke, and M. Mohammed, "Stakeholders Impact Analysis On Road Construction Project Management in Ethiopia: A Case Of Western Region," vol. 0869, no. 11, pp. 115-121, 2015.
[14] O. O. Ugwu; I. C. Attah, "AN APPRAISAL OF CONSTRUCTION MANAGEMENT PRACTICE IN NIGERIA,” Niger. J. Technol., vol. 35, no. 4, pp. 754-760, 2016. 